Journal of Computer Science 8 (1): 76-83, 2012

ISSN 1549-3636

(C) 2012 Science Publications

\title{
A Comparison between Electrical and Optical Chromatic Dispersion Compensation in Wavelength Divison Multiplexing Network Regarding to Electrical Pulse Shapes
}

\author{
Mohammad Syuhaimi Ab-Rahman and Majid Moghaddasi \\ Department of Electrical, Electronics and Systems, \\ Faculty of Engineering and Built Environment, \\ University Kebangsaan Malaysia, \\ 43600 UKM Bangi, Selangor, Malaysia
}

\begin{abstract}
Problem statement: Besides of some impairment that has been inherited form single channel, specialists confronted with new obstacles in WDM implementation which bared them for achieving desired performance. Although Chromatic Dispersion (CD) exists in single channel too, it can worsens new nonlinearities which are occurs just in WDM systems. So CD compensation in WDM is even more vital than single channel one. Approach: A wide range of optical and electrical CD compensation techniques have been represented. In this study we evaluate the efficiency of feed Forward-Decision Feedback Equalizer (FFE-DFE) as one type of electrical compensation methods and Dispersion Compensation Fiber as one type of optical compensator. Also we will look how electrical pulse shapes induced by pulse generator in transmitter, can impact on the performance of the either optical or electrical compensations. Results: After implementation, it was revealed that overall optical compensation with DCF gives us better performance than electrical equalizer and NRZ is more vulnerable than two other pulse shapes. Conclusion: Chromatic compensation was implemented with different pulse shapes and RZ pulse shape with optical compensation showed the best performance.
\end{abstract}

Key words: Chromatic Dispersion (CD), Forward-Decision Feedback Equalizer (FFE), Stimulated Raman Scattering (SRS), Bit Error Rate (BER), Maximum Likelihood Sequence Estimator (MLSE), Four-Wave Mixing (FWM)

\section{INTRODUCTION}

Instead of offering high transmission rate (bandwidth), survivability and security is the compensated features of the new optical network which used to cater the technologies evolved in the ICT application (Ab-Rahman et al., 2009a)(Ab-Rahman et al., 2009c)(Ab-Rahman and Mahir 2011). For example Internet traffic has been increasing at incredible rate ranging from $75-125 \%$ yearly. Current and future technologies such as VoIP, IPTV and Internet II and also IPV6 seek for a technology to satisfy their demands for much higher data rate and longer distance. At the same time, many devices and equipments have been invented to ensure these application received continously at the customer's house even in the case of network breakdown (Ab-Rahman et al., 2009a)(AbAdesta et al., 2010). Typical reach of optical networks in metropolitan area networks is around $300 \mathrm{~km}$. The network capacity can simply be increased by increasing the data rate from the existing 2.5-10 $\mathrm{Gb} \mathrm{sec}^{-1}$
(Bhandare et al., 2010). Although optical networks had provided much higher data rate and longer distance compare to conventional networks, but demands for ultra high data rate required researchers to find new technologies in optical networks. One of the most important techniques that have been invented in optical network is Wavelength Multiplex Division (WDM). It was a great milestone that gives capability for surging data rate transmission several times more than single channel. But it inherited single channel impairment and some of them even are more severe in WDM compare to single channel. Chromatic Dispersion (CD) is one of the most important of impairments that can induce undesired nonlinear effects beside its undesired effect on system performance. Additionally, The extension of optical wire up to the customer's desk through the POF-solution also contribute the high bandwidth demand application (Ab-Rahman et al., 2009b). The single red LED can offer the maximum data rate of $500 \mathrm{MHz}$ but with embedding POF-WDM technology (multiple LED) the customers can rich up their network up to $1 \mathrm{GHz}$. 
Chromatic dispersion: Fiber impairments such as Chromatic Dispersion (CD) severely impact the performance of high speed optical fiber transmission systems (Xu et al., 2009). It is one of the most important parameters and should be carefully analyzed during their design. In order to avoid power penalty due to nonlinear effects, in a long-hall transmission system optical fibers with small but nonzero chromatic dispersion is required (Patrocfnio da Silva et al., 2009). $\mathrm{CD}$ is one type of impairments that causes pulse broadening and occurs just in single mode fiber. It is induced because the energy of each propagated mode in SM fiber is dependent to the wavelength. For calculating of pulse broadening we assume that is $\beta$ propagation constant and $\Delta \omega$ is spectral with of the pulse. As a result the extension of the pulse broadening is represented by Eq. 1:

$\Delta \mathrm{T}=(\mathrm{dT} / \mathrm{d} \omega) \Delta \omega=\mathrm{L}\left(\mathrm{d}^{2} \beta / \mathrm{d} \omega^{2}\right) \Delta \omega=\beta_{2} \Delta \omega$

While we define Eq. 2:

$\beta_{2}=d^{2} \beta / d \omega^{2}$

As group velocity parameter which determines how much a pulse will be broadened inside a fiber. If we want to calculate it based on wavelength we earn Eq. 3 and 4:

$\Delta \mathrm{T}=\mathrm{D} \mathrm{L} \Delta \lambda$

While:

$\mathrm{D}=-2\left(\pi \mathrm{c} / \lambda^{2}\right) \beta_{2}$

$\mathrm{D}$ is named dispersion parameter and the unit of that is $\mathrm{ps} / \mathrm{nm} \mathrm{km}$. There are two factors which contribute chromatic dispersion; material dispersion and waveguide dispersion. If we represent Material Dispersion parameter with $\mathrm{D}_{\mathrm{M}}$ and waveguide dispersion with $\mathrm{D}_{\mathrm{W}}$ we will have Eq. 5:

$\mathrm{D}=\mathrm{D}_{\mathrm{M}}+\mathrm{D}_{\mathrm{W}}$

Material dispersion happens because the refractive index of silica varies with changing optical frequency $\omega$. fundamentally; the origin of material dispersion is relative to the characteristic resonance frequencies at which the material absorbs the electromagnetic waves. We can approximate material dispersion in the range of 1.25-1.66 $\mu \mathrm{m}$ of wavelength as following formula Eq. 6:

$\mathrm{D}_{\mathrm{M}}=122\left(1-\lambda_{\mathrm{ZD}} / \lambda\right)$ where, $\lambda_{\text {ZD }}$ is called zero dispersion wavelengths and is equal to $1.276 \mu \mathrm{m}$ for pure silica. $D_{M}$ is negative below this wavelength and is positive above it.

Waveguide dispersion $\mathrm{D}_{\mathrm{W}}$ is dependent to normalized frequency $\mathrm{V}$. Its major effect is shifting $\lambda_{\mathrm{ZD}}$ 30-40 nm which will cause that total dispersion become zero near 1.3-1.6 $\mu \mathrm{m}$.

Despite in SM fiber, we can increase BL factor strongly by operating at wavelength equal to $\lambda_{\mathrm{ZD}}$, to minimize $\mathrm{CD}$, but it is impossible to eliminate the effect of dispersion completely. Because of this fact that D cannot become zero at all wavelengths which exist within the pulse spectrum centered at $\lambda_{\mathrm{ZD}}$. Since D is dependent to the wavelength, it still causes pulse broadening. Here higher order dispersive effects concept is taken that are dominated by dispersion slope (differential-dispersion) Eq. 7:

$\mathrm{S}=\mathrm{dD} / \mathrm{d} \lambda$

It can be calculated as Eq. 8:

$S=\left(2 \pi c / \lambda^{2}\right)^{2} \beta_{3}+\left(4 \pi c / \lambda^{3}\right) \beta_{2}$

The value of the dispersion slope $\mathrm{S}$ has important factor in the design of WDM systems. If $S>0$, different channels will have slightly different GVD. So dispersion compensation will be difficult to be implemented for all channels. This problem can be solved by using new developed fibers which their slope $\mathrm{S}$ has been reached close to zero or even negative (Wooten et al., 2000).

Nonlinearities: There are several nonlinear factors which affect optical systems. Stimulated Raman Scattering (SRS) and Stimulated Brillouin Scattering (SBS) which are that correlate with the nonlinear inelastic scattering processes in fiber and also SelfPhase Modulation (SPM), Cross-Phase Modulation (XPM) and Four-Wave Mixing (FWM) which are generated because of intensity-dependent variations in the refractive index in a silica fiber. FWM, SBS and SRS cause gain to some channels, while loss to other ones that eventuate to crosstalk between the wavelength channels. While in single channel just SPM and SBS are in count, XPM, FWM and SRS are considered nonlinearities which belong to WDM systems.

SPM: It is generated when light confront with different refractive index when traverses along the fiber due to Kerr effect. As a result phase shift will be generated and it eventuates a change of pulse frequency spectrum. Refractive Index of optical material has little dependency to the optical Intensity Eq. 9: 
$\mathrm{n}=\mathrm{n}_{0}+\mathrm{n}_{2} \mathrm{I}=\mathrm{n}_{0}+\mathrm{n}_{2}\left(\mathrm{P} / \mathrm{A}_{\mathrm{eff}}\right)$

Here $\mathrm{n}_{0}$ is our ordinary refractive index, $\mathrm{n}_{2}$ is named nonlinear index coefficient. The factor $n_{2}$ is variable in silica from $2.2-3.4 \times 10-8 \mu \mathrm{m}^{2} \mathrm{~W}$. In formula (9), $n$ is real refractive index regarding to SPM effect. SPM converts optical power fluctuation to phase fluctuation in same wave (Keiser, 2003).

XPM: It is generated in WDM systems; it converts the fluctuations of the power in a particular channel into phase fluctuation in some other channels. It will be a big problem in long haul when data rate cross over $10 \mathrm{~Gb} \mathrm{sec}{ }^{-1}$.

FWM: Is a 3rd order nonlinearity in fibers that is generated because of the mixing of three optical frequencies: $\mathrm{v}_{\mathrm{i}}, \mathrm{v}_{\mathrm{j}}, \mathrm{v}_{\mathrm{k}}$. They generates new product $\mathrm{v}_{\mathrm{ijk}}$ that can be calculated by Eq. 10:

$\mathrm{v}_{\mathrm{ijk}}=\mathrm{v}_{\mathrm{i}}+\mathrm{v}_{\mathrm{j}}-\mathrm{v}_{\mathrm{k}} \mathrm{I}, \mathrm{j} \neq \mathrm{k}$

If new frequency $\mathrm{v}_{\mathrm{ijk}}$ falls in one of our original frequency, dire cross talk will be happened.

SBS: is issued from acoustic waves cause light wave scattering. Then in Single Mode Fiber (SMF) the resultant scattered wave, start to propagate as backward direction. It gets its power from original signals which are propagating as forward direction and so decreases their signal power (Keiser, 2003).

Chromatic dispersion compensation methods: Researchers have represented many techniques to eliminate or mitigate chromatic dispersion. We can classify them into two main groups: (1) an Optical compensation technique; that is premier technique for that goal. (2) Electrical compensation; that was considered before as auxiliary for compensation, but with improving the technology, it is going to be noticed more.

Electrical compensator: It is notable method to compensate dispersion at electrical part of receiver (or transmitter). It is a simple technique that doesn't need any changes in optical transmitting or receiving and also doesn't have considerable loss. Any network changes or adding new devices in the network can be done easily because of adaptive capability of electrical compensator. But there are some disadvantages of this system, for example circuits have limitation in speed compare to optical ones. There are several techniques for Electrical equalizer, such as: Feed Forward Equalizer (FFE), Feed Forward-Decision Feedback Equalizer (FFE-DFE), Nonlinear Feedforward-Decision Feedback Equalizer (NL-FFE-DFE) and Maximum Likelihood Sequence Estimator (MLSE).
Optical compensator: It is premier dispersion compensation method. Also optical compensation comprises several techniques; such as DCF, Fiber Brag Grating (FBG), Mid-span phase Conjugation, since in our experiment, we implement optical compensation with DCF, so we look explain about it.

DCF is a conventional with high performance solution to mitigate $\mathrm{CD}$. SSMF has low positive dispersion, while DCF has high negative one. In other words dispersion coefficient is much higher than ordinary fiber with opposite sign (usually between -80 , $-100 \mathrm{ps} \mathrm{km}^{-1} \mathrm{~nm}$ ). Commonly DCF length is used 4-20 times shorter than the transmission fiber length, so overall the arithmetic summation of the dispersion in the whole fiber will be zero. But on the other hand its attenuation is higher than ordinary fiber $(0.5-0.6 \mathrm{~dB}$ $\mathrm{km}^{-1}$ ). So we need to amplify the signal. The efficiency of using DCF in CD compensation in presence of SPM was shown by (Nuyts et al., 1997). DCF can be put at the beginning of main fiber, this method is named precompensation, or after fiber, which is named postcompensation and also subsequently at end and beginning of several fibers, which is named mixcompensation. It was shown that mix-compensation and then post-compensation have better performance than pre-compensation (Hu et al., 2010).

Input pulses and their correspondent coding: Electrical pulses induced by pulse generator, pulses then are sent to modulator (or diodes) to be converted into the optical signals. Here we represent three types of pulse shape that are used in our experiments:

Rectangular pulse: It is considered as one of the most important and premier kinds of pulse form which is an idealization of real impulse signals mathematically. After modulation they are coded into optical pulses. The most common techniques for coding is NRZ (Non return to zero) and RZ (Return to zero).

Triangular pulse: It is another important type of pulse forms. In some cases because it behaves more proper than rectangular form in some processes. One reason for this advantage is that its slopes are finite. The used coding in this experiment for triangular pulse shape is also RZ

\section{MATERIALS AND METHODS}

The motivation of this study is to compare the effect of input electrical pulse shape in electrical dispersion compensation and optical one (with DCF). We implemented an optical WDM network with four channels each one $10 \mathrm{~Gb} \mathrm{sec}{ }^{-1}$ data rate so transmit totally $40 \mathrm{~Gb} \mathrm{sec}^{-1}\left(4 \times 10 \mathrm{~Gb} \mathrm{sec}^{-1}\right)$ via a simple SMF with commercial simulator Optisystem 7.0 which is a product of the Optiwave Corporation. We consider 50 
$\mathrm{GHz}$ as frequency space between channels. So we assign current following channels and frequency:

Channel 1: $193.05 \mathrm{THz}$

Channel 2: $193.10 \mathrm{THz}$

Channel 3: $193.15 \mathrm{THz}$

Channel 4: $193.20 \mathrm{THz}$

All channels waves are modulated by MZM modulator. External modulator is used because it is recommended for bitrate at $10 \mathrm{~Gb} \mathrm{sec}^{-1}$ and higher. Via pulse generator, we apply NRZ, RZ and Triangular pulse form with data rate $10 \mathrm{~Gb} \mathrm{sec}^{-1}$. injected power is considered $0 \mathrm{dBm}$. In Table 1 we see other configurations of the network.

Also common noises such as ASE and shot noise is applied to system to be more actual. As we can observe, PMD has been disabled to just $C D$ affects on the system. But whereas higher order of GVD is effect the system performance considerably, they have been applied (Wooten et al., 2000).

Performance parameters: In this study two performance parameters are used to assess the system performance: Bit Error Rate (BER) and Eye diagram. BER is the probability of number of errors of bits that occurs during data transmission. Commonly the maximum acceptable of BER for optical communication system is $10^{-9}$. On the other hand eye diagram is a technique that provides an aggregation of signal measurement information and so helps us to evaluate the quality of the received signal. The quality of signal is assessed based on eye opening size. Since jitter is an error in time domain, it can cause phase distortion and noise producing.

CD compensation with electrical equalizer: In this method we need to add an electrical compensator and low pass filter after photodetector. Also an electrical limiter is added exactly before our electrical compensator. In our experiment we utilized FFEDFE method, because it is a simple method and consume power reasonably (Watts, 2005). In our experiment Forward taps coefficients is equal to 13 with taps space equal to 2 . Feedback taps coefficients were considered equal to 2 . In Fig. 1 we observe a schema of Receiver part of the implemented electrical compensation.

CD compensation with DCF: We can utilize a DCF and an extra amplifier for that. But since the length of the SSMF varies, we must vary the length of the DCF and its correspondent amplifier gain regarding to its length (Table 2). Among the methods on aspect of the place of DCF, we chose post-compensation. Because it has better performance compare to pre-compensation ( $\mathrm{Hu}$ et al., 2010) (We don't have mix-compensation in one span that is implemented in our experiment).

Since the GVD in SSMF is $16 \mathrm{ps} \mathrm{km}^{-1} \mathrm{~nm}$ and in DCF is $-90 \mathrm{ps} \mathrm{km} \mathrm{km}^{-1} \mathrm{~nm}$ with formula (12) we can achieve the required length for DCF Eq. 11-13:

$\mathrm{L}_{\mathrm{DCF}}=\left(\mathrm{L}_{\mathrm{SMF}} \times \mathrm{D}_{\mathrm{SMF}}\right) / \mathrm{D}_{\mathrm{DCF}}$

On the other hand attenuation is a considerable property of DCF which is its high $\left(0.6 \mathrm{~dB} \mathrm{~km}^{-1}\right)$. Of course for a fair result comparison between electrical and optical compensator, we need to add an amplifier to the link including of the DCF.

Thus we determine the required extra gain of amplifier for a particular length of the optical link with following formula:

$\mathrm{G}=\alpha_{\mathrm{DCF}} \times \mathrm{L}_{\mathrm{DCF}}$

Since $\alpha_{\mathrm{DCF}}=0.6 \mathrm{~dB} \mathrm{~km}^{-1}$ we can attain gain of amplifier for each length:

$\mathrm{G}=0.6 \times \mathrm{L}_{\mathrm{DCF}}$

Table 1: Summary of network components configurations

\begin{tabular}{|c|c|}
\hline Bit sequence generator & Bitrate: $10 \mathrm{~Gb} \mathrm{sec}^{-1}$ \\
\hline Pulse generator & $\begin{array}{l}\text { (NRZ, RZ, Triangular) rectangular shape: } \\
\text { Gaussian-duty cycle: } 0.67\end{array}$ \\
\hline CW laser & $\begin{array}{l}\text { bit Frequency: } 193.1 \mathrm{THz}-\text { Power: } 0 \mathrm{~dB} \mathrm{~m} \\
\text {-Linewidth: } 10 \mathrm{MHz}\end{array}$ \\
\hline \multicolumn{2}{|c|}{ Mach-zehnder modulator Extinction ratio: $10 \mathrm{~dB}$} \\
\hline Optical amplifier & Gain Control: $15 \mathrm{~dB}$-noise figure: $4 \mathrm{~dB}$ \\
\hline \multirow[t]{4}{*}{ Optical fiber } & $\begin{array}{l}\text { Attenuation: } 0.2 \mathrm{~dB} \mathrm{~km}^{-1}-\mathrm{GVD} \text { : } \\
16 \mathrm{ps} \mathrm{nm}^{-1} \mathrm{~km} \text { dispersion slope: }\end{array}$ \\
\hline & 0.085 ps $\mathrm{km}^{-1} \mathrm{~nm}^{2}$-PMD: 0 DC fiber \\
\hline & Attenuation: $0.6 \mathrm{~dB} \mathrm{~km}^{-1}$-GVD:-90 ps nm${ }^{-1}$ \\
\hline & $\begin{array}{l}\text { km -dispersion slope: } 0.21 \mathrm{ps} \mathrm{km}^{-1} \mathrm{~nm}^{2} \\
\text {-PMD: } 0\end{array}$ \\
\hline PIN photodetector & Dark current: $10 \mathrm{nA}-$ Responsivity $1 \mathrm{~A} / \mathrm{W}$ \\
\hline Lowpass filter & Cutoff Frequency: $0.75^{*}$ : bitrate HZ \\
\hline Electrical equalizer & Reference bitrate $10 \mathrm{~Gb} \mathrm{sec}^{-1}$-step size: 0.3 \\
\hline BER analyzer & Algorithm: Gaussion-time window: 1.5 bit \\
\hline
\end{tabular}

Table 2: Required DCF length and correspondent amplifier

\begin{tabular}{llr}
\hline $\begin{array}{l}\text { Length of } \\
\text { SMF }(\mathrm{km})\end{array}$ & $\begin{array}{l}\text { Required length } \\
\text { of DCF }(\mathrm{km})\end{array}$ & $\begin{array}{l}\text { Required amplifier } \\
\text { gain }(\mathrm{dB})\end{array}$ \\
\hline 70 & 12.4 & 7.44 \\
80 & 14.2 & 8.52 \\
90 & 16.0 & 9.60 \\
100 & 17.7 & 10.62 \\
110 & 19.5 & 11.70 \\
120 & 21.3 & 12.78 \\
130 & 23.1 & 13.86 \\
140 & 24.8 & 14.88 \\
150 & 26.6 & 15.96 \\
160 & 28.4 & 17.04 \\
\hline
\end{tabular}




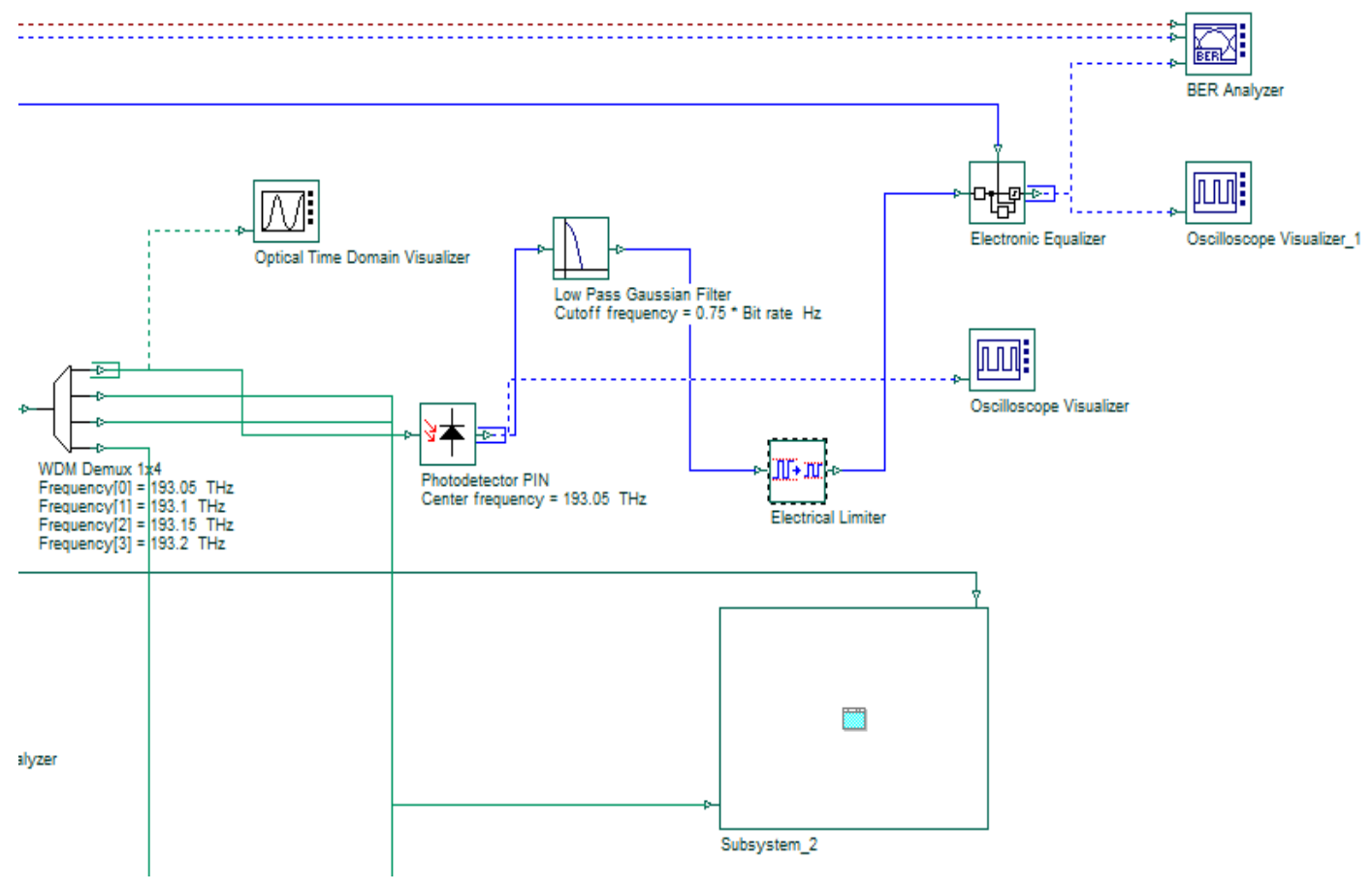

Fig. 1: A schema of Receiver part of implemented WDM network

\section{RESULTS}

CD compensation with electrical equalize: In Fig. 2 we observe that NRZ can restrict us to increase distance even less than $100 \mathrm{~km}$. With distance of $100 \mathrm{~km}$ and more, the received signal is so distorted and weak that cannot be desired. The maximum attained performance by NRZ, occurs at $90 \mathrm{~km}$ and after that the signal loses its quality. Also RZ give us little better performance. The maximum acceptable distance with RZ pulse shape is $100 \mathrm{~km}$. with increasing the distance the quality of received signal with RZ worsens so that after we get obscure signal. It gives us the best performance at distance $80 \mathrm{~km}$. In this situation, Triangular pulse shape gives us a little bit better performance. Although after $100 \mathrm{~km}$ the quality of signal decreased toward unacceptable value, throughout the variation distance from $70-160 \mathrm{~km}$, it gives us better performance than RZ and NRZ.

\section{CD compensation with optical compensation} (DCF): In Fig. 3, we observe that NRZ can give acceptable performance from $70 \mathrm{~km}$ until the end. The curves do not include considerable variation and $\mathrm{RZ}$ on the other hand give us much better signal quality than NRZ. It improves the performance with increment of the distance and keeps its good performance until the end. Triangular pulse form also gives acceptable performance and its signal quality is something between RZ and NRZ although is more near to RZ.

Now we make compensation between electrical and optical compensation on aspect of jitter. Fig. 4-7 is the results of the implementation via electrical and optical compensation. As we observe in both Fig. 4 and 5 , decision instant is implemented at 0.5 bit period. So we scrutinize to timing jitter in right part of diagram (after electrical compensation).

We attain eye diagram while implement triangular pulse shape at transmitter. With electrical compensation we observe jitter is equal to 0.192566 of bit period after $70 \mathrm{~km}$ distance. Then we attain the result after just $50 \mathrm{~km}$ increment of the distance $(120$ $\mathrm{km})$. We gain jitter equal to 0.308633 of bit period.

It means the jitter is increased 0.116067 bit period just after $50 \mathrm{~km}$. Now we implement same experiment with optical compensator. After $70 \mathrm{~km}$ we attain 0.0580336 bit period as jitter. After increment $50 \mathrm{~km}$ (after $120 \mathrm{~km}$ ) we achieve signal with jitter equal to 0.0738609 bit period. It means the jitter in optical compensation is increased just 0.0158273 bit period. 


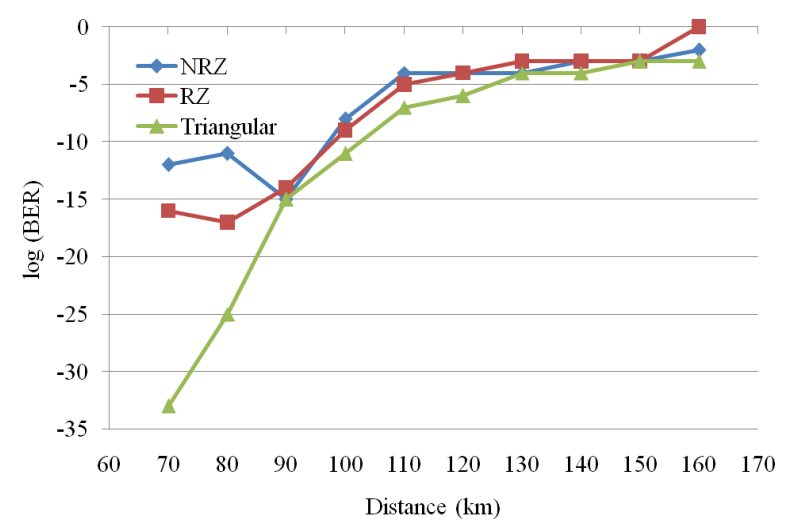

Fig. 2: CD Compensation with electrical equalizer

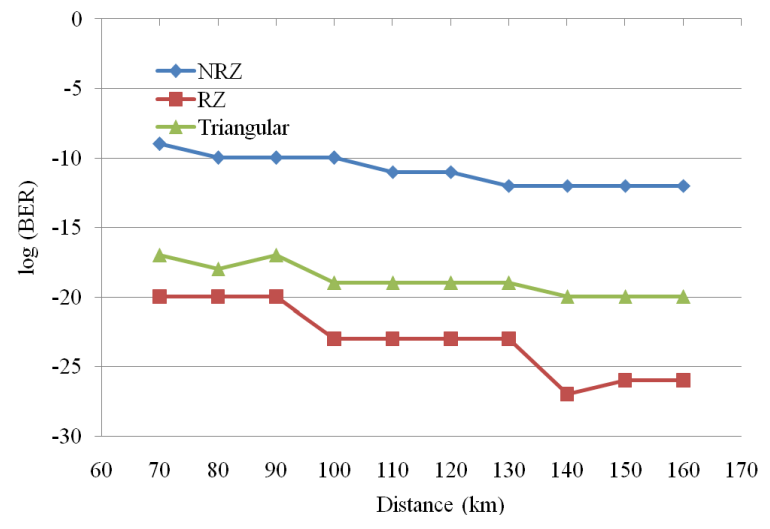

Fig. 3: CD compensation DCF

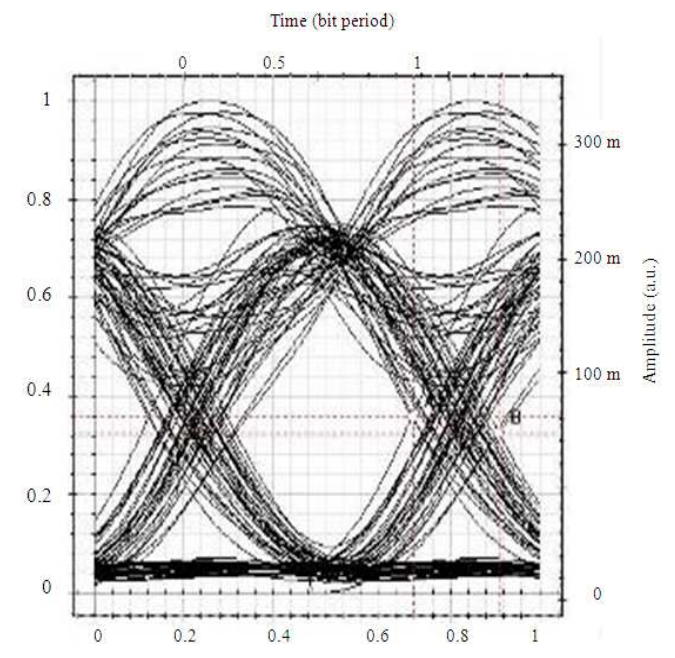

Fig. 4: Electrical compensation with NRZ, $70 \mathrm{~km}$ distance

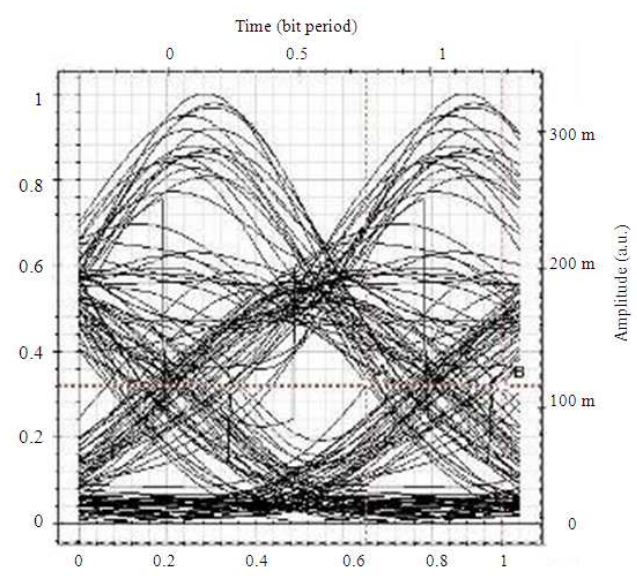

Fig. 5: Electrical compensation with NRZ, $120 \mathrm{~km}$

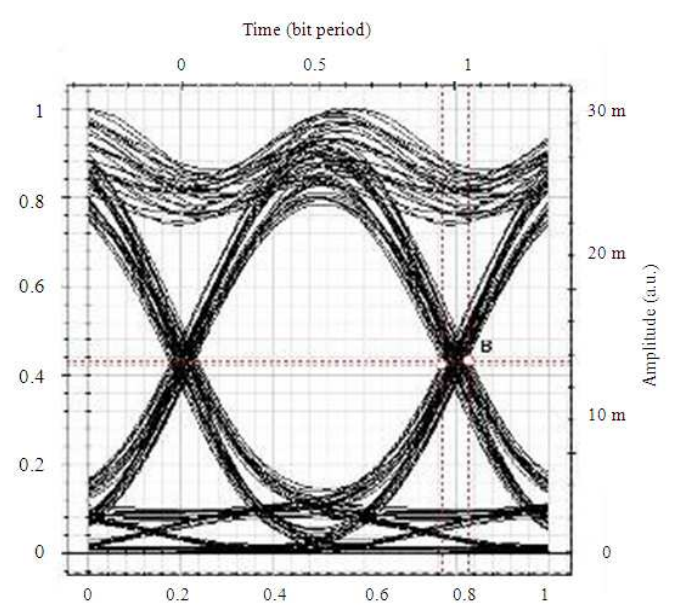

Fig. 6: Optical compensation with NRZ, $70 \mathrm{~km}$ distance

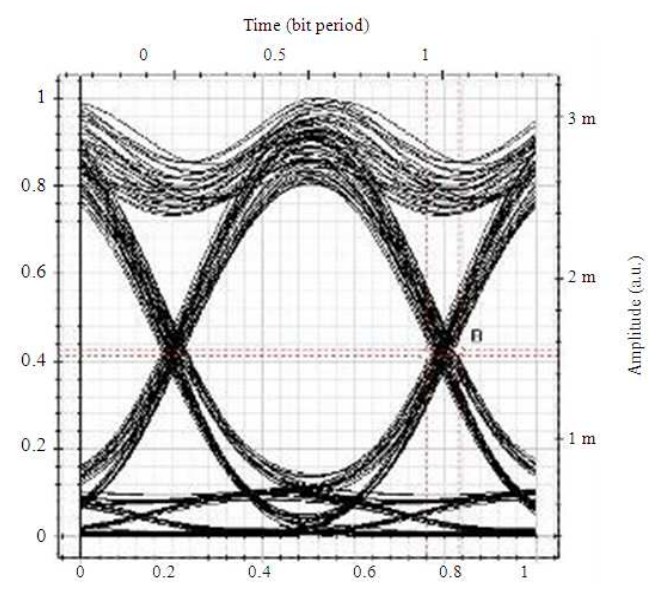

Fig. 7: Optical compensation with NRZ, $120 \mathrm{~km}$ 


\section{DISCUSSION}

CD compensation with electrical equalizer: From the overall result, we concluded that NRZ give us less performance than others. Despite in electrical compensation in point-to-point topology, NRZ predominates at some distances, it almost gives up in WDM topology in whole the route. The reason is that in WDM 2nd order of chromatic dispersion affects the signal which was not in count in point-to point; and NRZ is more susceptible against 2nd order of CD (Breuer and Petermann, 1997).

CD compensation with optical compensation (DCF): From the result, we can see that RZ shows a definite better performance and this is because that in the presence of nonlinearities and 1st and 2nd order of CD, RZ give us better performance (Park et al., 2000). Overall although all three types of signals are good enough, RZ is the best choice.

From the eye-diagram, we concluded that even with dispersion compensation we still have a big problem for increment of the maximum available distance with electrical compensator. Because with distance increment, the jitter increases hugely and this will bar us to achieve to longer distance. This result had been is correspond with achievement by (Pinto et al., 2006).

Another main point that must be considered is the cost. In a one-span point-to-point we can just use one optical compensator versus one electrical equalizer at receiver which can be competitive to each other in cost that commonly electrical compensation is more reasonable in price than optical one. On the other hand since optical compensator has capability of compensation for several wavelengths simultaneously, one optical compensator suffices for WDM network. But with electrical compensator, we must assign one equalizer for each wavelength. Consequently based on the number of channels, we must provide equalizer which surge the cost. It makes optical compensator more attractive in WDM networks.

\section{CONCLUSION}

Optical networks are analogue in nature and suffer from a variety of linear and nonlinear transmission impairments. These effects have a direct impact on the bit error rate (BER) performance of the system and most importantly, this impact increases in systems supporting higher data rates and larger number of channels (Papagiannakis et al., 2008).

In this study, chromatic dispersion compensation via electrical equalizer (with FFE-DFE method) and optical compensator (with DCF) were compared and the role of electrical pulse mode in them was investigated. In all situations NRZ showed more susceptible to $\mathrm{CD}$ than $\mathrm{RZ}$ and Triangular pulse form. On the other hand, with Electrical Equalizer, Triangular pulse shape is the best choice, while with Optical compensation RZ is better.

On aspect of electrical versus optical compensation, except for short distance with Triangular pulse mode, overall optical compensation gives us better performance. Also on aspect of jitter, electrical compensation shows that with distance increment, the jitter is accumulated which is a big problem for distance development in electrical compensations. Also on aspect of the cost, it seems electrical compensation lost its advantage in WDM; especially if the number of channels be big enough.

As future work it is recommended to investigate the behavior and diversity of different pulses and modulations in negative and positive dispersion.

\section{ACKNOWLEDGEMENTS}

The researchers would like to acknowledge University Kebangsaan Malaysia for supporting this research by providing equipment, material and sources of references in accomplishing this research and also my supervisor Dr. Mohammad Syuhaimi Ab-Rahman for his guides.

\section{REFERENCES}

Ab-Rahman, M.S., S.A.C. Aziz and K. Jumari, 2009a. Protection for an immediate split structure of TreeBased EPON architecture-ideal condition analysis. Am. J. Eng. Applied Sci., 2: 372-380. DOI: 10.3844/ajeassp.2009.372.380

Ab-Rahman, M.S., H. Guna, M.H. Harun, S.D. Zan and K. Jumari, 2009b. Cost-effective fabrication of self-made $1 \times 12$ polymer optical fiber-based optical splitters for automotive application. Am. J. Eng. Applied Sci., 2: 252-259. DOI: 10.3844/ajeassp.2009.252.259

Ab-Rahman, M.S., B. Ng, R.M. Ibrahim and S. Shaari, 2009c. Low-cost encoding device for optical code division multiple access system. Am. J. Eng. Applied Sci., 2: 317-323. DOI: 10.3844/ajeassp.2009.317.323.

Wooten, E.L., K.M. Kissa, A. Yi-Yan, E.J. Murphy and D.A. Lafaw et al., 2000. A review of lithium niobate modulators for fiber-optic communications systems. Selec. Topics Quantum Elec. IEEE J., 6: 69-82. DOI: 10.1109/2944.826874

Bhandare, S., A. Joshi and D. Becker, 2010. Optical coherent receiver with a switchable electrical 
dispersion compensator for $10 \mathrm{~Gb} \mathrm{sec}^{-1}$ DPSK transmission up to $300 \mathrm{~km}$ of SSMF in metro optical networks. J. Lightwave Technol., 28: 47-58.

Breuer, D. and K. Petermann, 1997. Comparison of NRZand RZ-modulation format for $40-\mathrm{Gb} \mathrm{sec}^{-1} \mathrm{TDM}$ standard-fiber systems. IEEE Photon. Technol. Lett., 9: 398-400. DOI: $10.1109 / 68.556086$

Hu, B.N., W. Jing, W. Wei and R.M. Zhao, 2010. Analysis on dispersion compensation with DCF based on optisystem. Proceeding of the 2nd International Conference on Industrial and Information Systems, July 10-11, IEEE Xploor, Dalian, $\quad$ pp: 40-43. DOI: 10.1109/INDUSIS.2010.5565685

Keiser, G., 2003. Optical Communications Essentials. 1st Edn. The McGraw-Hill, New York, pp: 373.

Nuyts, R.J., Y.K. Park and P. Gallion, 1997. Dispersion equalization of a $10 \quad \mathrm{~Gb} \quad \mathrm{sec}^{-1}$ repeatered transmission system using dispersion compensating fibers. J. Lightwave Tech., 15: 31-42. DOI: $10.1109 / 50.552111$

Papagiannakis, I. et al., 2008. Electronic distortion compensation in the mitigation of optical transmission impairments: the view of joint project on mitigation of optical transmission impairments by electronic means ePhoton/ONe1 project. IET Optoelect., 3: 73-85. DOI: 10.1049/ietopt.2008.0032

Park, S.G., A.H. Gnauck, J.M. Wiesenfeld and L.D. Garrett, 2000. 40-Gb $\sec ^{-1}$ transmission over multiple $120-\mathrm{km}$ spans of conventional singlemode fiber using highly dispersed pulses. IEEE Photon. Technol. Lett., 12: 1085-1087. DOI: $10.1109 / 68.868016$
Patrocfnio da Silva, J., D.S. Bezerra, I.E. Fonseca, V.F. Rodriguez-Esquerre and H.E. Hernandez-Figueroa, 2009. Photonic crystal fiber design with Ge-doped core for residual chromatic dispersion compensation. Proceeding of the IEEE MTT-S International Microwave and Optoelectronics Conference, Nov. 3-6, ieee xploor, Belem, pp: 787791. DOI: 10.1109/IMOC.2009.5427471

Pinto, A.N., J.R.F.D.A Rocha, Q. Lin and G.P. Agrawal, 2006. Optical versus electrical dispersion compensation: Role of timing jitter. J. Lightwave, Techn., 24: 387-395. DOI: 10.1109/JLT.2005.860153

Watts, P.M., 2005. Performance of single-mode fiber links using electronic feed-forward and decision feedback equalizers. IEEE Photon. Technol. Lett., 17: 2206-2208. DOI: 10.1109/LPT.2005.856326

Xu, T., G. Jacobsen, S. Popov, J. Li, K. Wang and A.T. Friberg, 2009. Digital Compensation of Chromatic Dispersion in 112-Gbit $\sec ^{-1}$ PDM-QPSK system. Proceeidng of the Asia Communications and Photonics Conference and Exhibition, Technical Digest, Nov. 2, Optical Society of America,Shanghai, China, pp: 1-3.

Adesta, E.Y.T., A.M. Ali, D. Agusman, M. Riza and M.Y. Suprianto, 2010. A study of parameters relationship to backcutting phenomena during high speed end milling of AISI H13. Am. J. Applied Sci., 7 : $1420-1425 . \quad$ DOI: 10.3844/ajassp.2010.1420.1425 